\title{
Regulatory roles of cell surface sialylation in sphingolipid- induced cell death in human B cell lymphoma
}

\author{
OSAMU SUZUKI, YOSHIHIRO NOZAWA and MASAFUMI ABE
}

\author{
First Department of Pathology, School of Medicine, Fukushima Medical University, Fukushima, Japan
}

Received May 16, 2006; Accepted June 26, 2006

\begin{abstract}
Sphingolipid metabolites are important regulators of cell growth and death. In the present study, we examined the function of cell surface sialic acid in exogenous sphingosine1-phosphate (S-1-P) or sphingosine-induced cell death. HBL-2 human diffuse large B cell lymphoma cells were incubated with or without Vibrio Cholerae neuraminidase followed by S-1-P or sphingosine. Flow cytometric analysis using Limax flavus agglutinin, a sialic acid-specific lectin, showed that sialylated glycoconjugates are present on the surface of HBL-2 cells and that they were removed by neuraminidase. In addition, the pretreatment with neuraminidase enhanced S-1-P- and sphingosine-induced cell death, an effect that was not dependent on caspase activation. Furthermore, the cell death induced by S-1-P and sphingosine was morphologically distinct from apoptosis. We further examined S-1-P-induced cell death in two clones of HBL-8 Burkitt lymphoma cells with different amounts of cell surface sialic acid. Clone 3G3, which is hypersialylated, was less sensitive to S-1-P than the 3D2 clone, which is hyposialylated, suggesting that the extent of surface sialylation influences the sensitivity to S-1-P. In conclusion, S-1-P and sphingosine induce cell death, and the sensitivity of human B lymphoma cells to these agents appears to depend on the amount of sialic acid on their cell surfaces.
\end{abstract}

\section{Introduction}

Sialic acid plays an important role in tumor cell behavior by affecting adhesion, invasiveness and metastasis (1-11), thereby influencing clinical outcome $(12,13)$. The role of sialic acid as a biological mask of surface structures is well documented (14), and cell surface sialylation of thymocytes and myeloid cells is closely associated with their maturation and differentiation $(15,16)$. Cell surface sialylation regulates Fas-induced apoptosis in lymphoma cells $(17,18)$, and we previously showed that this occurs in human $\mathrm{T}$ cell lymphoma in a

Correspondence to: Dr Osamu Suzuki, Fukushima Medical University, School of Medicine, Department of Pathology, 1 Hikarigaoka, Fukushima 960-1295, Japan

E-mail: osuzuki@fmu.ac.jp

Key words: human malignant lymphoma, sialic acid, sphingolipids, cell death caspase-dependent manner (19). Uridine diphosphate-Nacetylglucosamine 2-epimerase (UDP-GlcNAc2-epimerase) is a key enzyme in sialic acid biosynthesis (20), and expression of UDP-GlcNAc2-epimerase mRNA was found to correlate with sialic acid content in two clones of HBL-8 Burkitt lymphoma cells (21). Furthermore, expression of UDPGlcNAc2-epimerase mRNA may regulate the expression of sialoglycoconjugates, which affect the adhesion of Burkitt's lymphoma cells to collagen type IV and fibronectin (21).

Sphingolipids are structural components of the cell membrane that play a key role in cell signaling (22-27). Sphingosine-1-phosphate (S-1-P) is a bioactive sphingolipid metabolite and is present in serum $(28,29)$. S-1-P plays an important role in the regulation of a variety of biological processes through intracellular or extracellular mechanisms (23). The endothelial differentiation gene (EDG) family of $\mathrm{G}$-protein-coupled receptors act as receptors for S-1-P $(24,25,31)$. S-1-P is released from activated platelets and in allergically stimulated mast cells, and it is secreted by erythrocytes, neutrophils, and mononuclear cells (30). S-1-P is a novel inhibitor of $\mathrm{T}$ cell proliferation and maintains the homeostatic immune system $(31,32)$. Previous reports indicate that S-1-P triggers apoptotic signals in human hepatic myofibroblasts $(24,25)$ and induces cell death in a hepatoma cell line (26).

Sphingosine is another bioactive sphingolipid that has various cellular roles, including inhibition of protein kinase $\mathrm{C}$ (33) and induction of apoptosis in HL-60 cells (34). Sphingosine also induces necrotic cell death (35) and is involved in tumor necrosis factor (TNF)- $\alpha$-induced apoptosis in neutrophils (36).

In the present study we show that alteration in cell surface sialylation modulates S-1-P or sphingosine-induced cell death. This suggests a novel role of sialic acid in the regulation of sphingolipid-induced cell death.

\section{Materials and methods}

Cell lines. HBL-2 and HBL-8 are human diffuse large B cell lymphoma and human Burkitt lymphoma cell lines, respectively (10,37). HBL-2 and HBL-8 cells were grown at $37^{\circ} \mathrm{C}$ in RPMI-1640 containing $15 \%$ fetal calf serum and in an atmosphere containing $5 \% \mathrm{CO}_{2}$. Two clones of HBL-8 (3G3 and 3D2) show different reactivities to Soybean agglutinin (SBA) and Vicia villosa agglutinin (VVA) lectins as well as different metastatic capacities in the SCID mouse model (10). These clones have different amounts of cell surface sialic 
acid due to differences in the expression of UDP-GlcNAc2epimerase, which is a key enzyme in sialic acid biosynthesis (21).

Antibodies and reagents. Biotinylated Limax flavus agglutinin (LFA), which is a sialic acid-specific lectin, was from EY Laboratories (San Mateo, CA, USA). Neuraminidase from Vibrio Cholerae was purchased from Roche (Germany). The caspase inhibitor carbobenzoxy-L-valyl-ß-methyl-L-aspart-1fluoromethane (z-VAD-fmk) was obtained from Peptide Institute, Inc. (Japan) and was dissolved in dimethyl sulfoxide. Anti-CDw76 monoclonal antibody (clone BL-B8), which reacts with sialic acid-linked gangliosides, was purchased from Monosan (The Netherlands). Mouse monoclonal antibody G155-228 (BD PharMingen, USA) was used for isotype control studies.

Flow cytometry. HBL-2 cells ( $5 \times 10^{5}$ cells) were suspended in $100 \mu 1$ of phosphate-buffered saline (PBS) and incubated at $4^{\circ} \mathrm{C}$ for 20 min with $5 \mu 1$ of biotinylated lectins or anti-CDw76 monoclonal antibody and then washed twice with PBS. Next, the cells were incubated at $4^{\circ} \mathrm{C}$ for 20 min with $5 \mu 1$ of avidinfluorescein isothiocyanate (FITC; Vector Laboratories, Inc., Burlingame, CA, USA) or FITC-conjugated anti-mouse immunoglobulins (Biosource, CA, USA) and washed twice with PBS. Fluorescent intensities were analyzed on a FACScan (Becton-Dickinson, Mountain View, CA, USA). To analyze cell surface sialylation, $6 \times 10^{6}$ cells were incubated at $37^{\circ} \mathrm{C}$ for 30 min in $200 \mu 1$ of RPMI-1640 containing $15 \%$ fetal calf serum and $40 \mu 1$ of $1 \mathrm{U} / \mathrm{ml}$ Vibrio Cholerae neuraminidase (Boehringer Mannheim, Germany) before incubation with biotinylated lectins (19).

Effects of neuraminidase on S-1-P-and sphingosine-induced cell death. Cell viability was assessed using a WST-1 assay kit (Boehringer Manheim) (19). HBL-2 cells or HBL-8 clones $3 \mathrm{G} 3$ and 3D2 were grown for two days and then seeded for $30 \mathrm{~min}$ at $37^{\circ} \mathrm{C}$ in 96 -well microtiter plates at $5 \times 10^{4}$ cells/ well in $120 \mu 1$ phenol red- and serum-free culture medium containing $7.5 \mu \mathrm{M} \mathrm{S}-1-\mathrm{P}$ or $10 \mu \mathrm{M}$ sphingosine (Biomol Research Laboratories, Inc., USA) in the presence or absence of $120 \mu \mathrm{M} \mathrm{z}$-VAD-fmk. Next, $10 \mu \mathrm{l}$ of WST-1 reagent was added to each well, and the plates were incubated for $2 \mathrm{~h}$ at $37^{\circ} \mathrm{C}$. The plates were then shaken for $1 \mathrm{~min}$ at room temperature, and the absorbance at 450-655 $\mathrm{nm}$ was measured using a model 550 microplate reader (Bio-Rad, CA, USA). To evaluate the effects of cell surface desialylation, $6 \times 10^{6}$ cells were incubated at $37^{\circ} \mathrm{C}$ for $30 \mathrm{~min}$ in $200 \mu \mathrm{l}$ of RPMI-1640 containing $15 \%$ fetal calf serum and $40 \mu 1$ of $1 \mathrm{U} / \mathrm{ml}$ Vibrio Cholerae neuraminidase (Boehringer Mannheim) before incubation with S-1-P or sphingosine.

Morphology of cell death. Giemsa-stained Cytospin ${ }^{\circledR}$ HBL-2 cell preparations were evaluated for morphological changes during S-1-P- or sphingosine-induced cell death.

Annexin-V assay. HBL-2 cells $\left(2 \times 10^{6}\right)$ were treated with serum-free culture medium containing S-1-P (Biomol Research Laboratories, Inc.) at a final concentration of $3.75 \mu \mathrm{M}$. After $30 \mathrm{~min}$, the cells were incubated with $20 \mu \mathrm{l}$ of Annexin VFITC and $20 \mu 1$ of propidium iodide (PI) according to the a

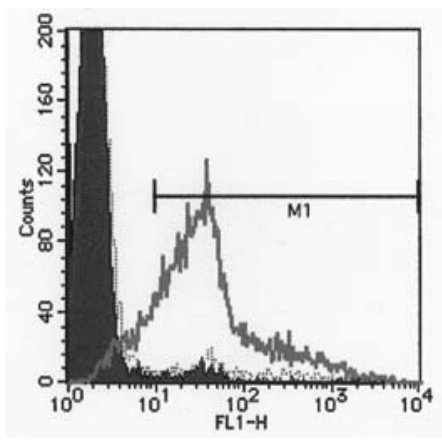

b
$3 G 3$

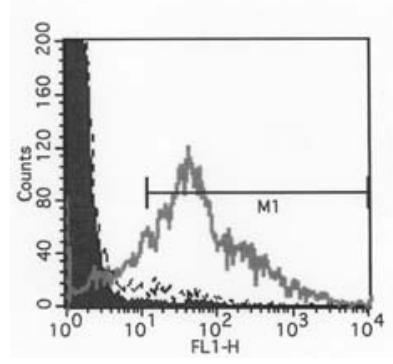

c

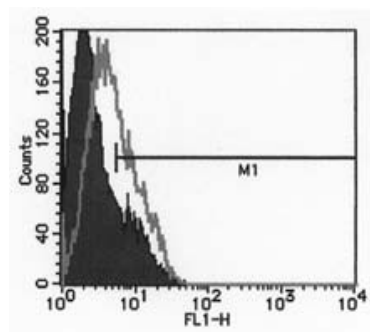

Neuraminidase (-)
3D2

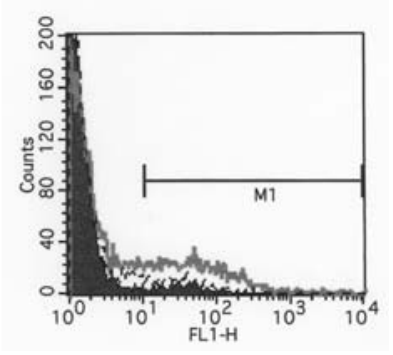

d

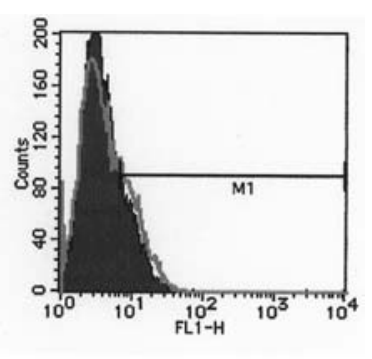

Neuraminidase (+)
Figure 1. Analysis of cell surface sialylation by flow cytometry. (a) Cell surface sialylation in HBL-2 cells. The thick and dotted lines show LFA binding without and with neuraminidase treatment, respectively. Stippled areas indicate the negative controls. LFA lectin binding was eliminated by neuraminidase treatment, indicating the removal of cell surface sialic acids. (b) Cell surface sialylation in the 3G3 and 3D2 clones of HBL-8 cells. Solid and dotted lines show LFA binding without or with neuraminidase treatment. Stippled areas indicate the negative controls. Substantial LFA lectin binding was found in the $3 \mathrm{G} 3$ clone, but only weak binding was found in the 3D2 clone. (c) Detection of gangliosides on HBL-2 cells by an anti-CDw76 monoclonal antibody. The anti-CDw76 monoclonal antibody bound in the absence of neuraminidase treatment. (d) Binding of the anti-CDw76 monoclonal antibody to the HBL-2 cell line was eliminated by neuraminidase treatment.

manufacturer's instructions (Roche, Tokyo, Japan). The fluorescence intensity from fluorescein and PI intensity were analyzed with a FACScan (Becton-Dickinson).

\section{Results}

Cell surface sialylation on HBL-2 and HBL-8 clones. Flow cytometry analysis showed that LFA, a sialic acid-specific lectin, reacted with the surface of HBL-2 cells. LFA lectin reactivity was completely eliminated by treatment with neuraminidase, indicating removal of cell surface sialic acids (Fig. 1a). The 3G3 clone of HBL-8 cells showed substantial cell surface binding of LFA lectin, but little binding was exhibited by the 3D2 clone (Fig. 1b). Furthermore, binding of 
$\mathbf{a}$

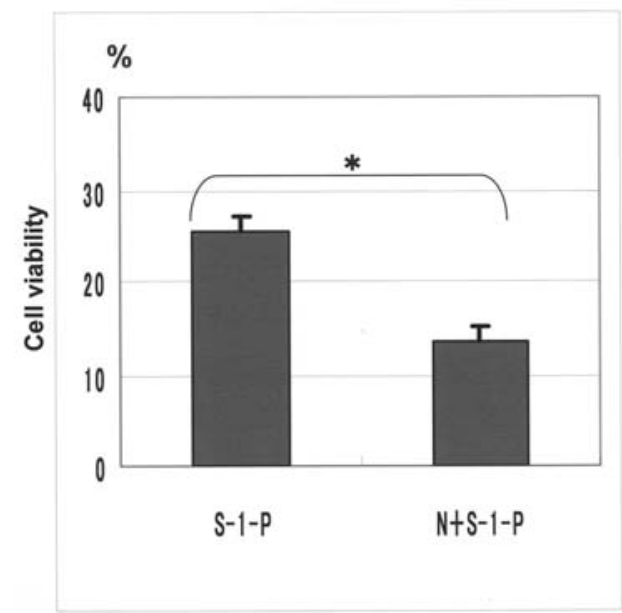

b

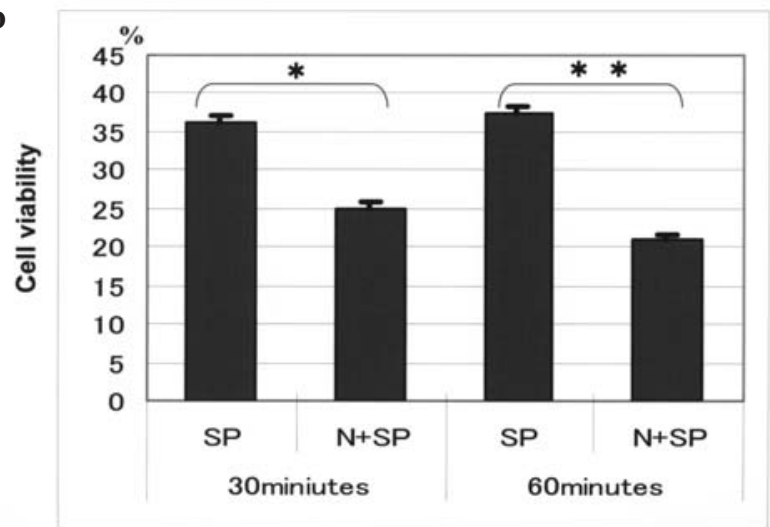

Figure 2. Effects of neuraminidase on S-1-P or sphingosine-induced cell death on the HBL-2 cell line. (a) Effect of S-1-P on cell viability as assessed with a WST-1 assay. Cells were incubated with $7.5 \mu \mathrm{M} \mathrm{S}-1-\mathrm{P}$. Cell viability of HBL-2 cells was decreased following incubation with S-1-P without or with neuraminidase treatment (25\% and $13 \%$, respectively). This shows that S-1-Pinduced cell death was markedly enhanced by neuraminidase treatment. $\mathrm{N}$, with neuraminidase treatment. ${ }^{~} \mathrm{P}=0.0009$ as determined by Student's t-test. Values represent the mean cell viability $\pm \mathrm{SD}$. The experiment was performed in triplicate. (b) Effect of sphingosine on cell viability was assessed using a WST-1 assay. Cells were incubated with $10 \mu \mathrm{M}$ sphingosine. The viability of HBL-2 cells was decreased by sphingosine without or with neuraminidase treatment (35\% and $25 \%$, respectively). This shows that sphingosine-induced cell death was markedly enhanced by neuraminidase treatment. SP, sphingosine; $\mathrm{N}$, with neuraminidase treatment. ${ }^{*} \mathrm{P}<0.0001$, ${ }^{* *} \mathrm{P}<0.0001$ as determined by Student's t-test. Values represent the mean cell viability $\pm \mathrm{SD}$. The experiment was performed in triplicate.

the anti-CDw76 monoclonal antibody was detected without neuraminidase treatment (Fig. 1c), but it was completely eliminated with neuraminidase pretreatment (Fig. 1d). This finding suggests that CDw76 is $\alpha 2,6$-linked ganglioside and CDw76 ganglioside is converted to the asialo-form with neuraminidase treatment.

Effect of neuraminidase treatment on S-1-P- or sphingosineinduced cell death. Serum-deprived HBL-2 cells or HBL-8 clones were incubated with or without S-1-P or sphingosine. The viability of HBL-2 cells decreased when they were incubated with S-1-P in the absence or presence of neuraminidase treatment (25\% and $13 \%$, respectively; Fig. $2 \mathrm{a})$. Also, the viability of HBL-2 cells decreased when they were incubated for 30 min with sphingosine in the absence or presence of

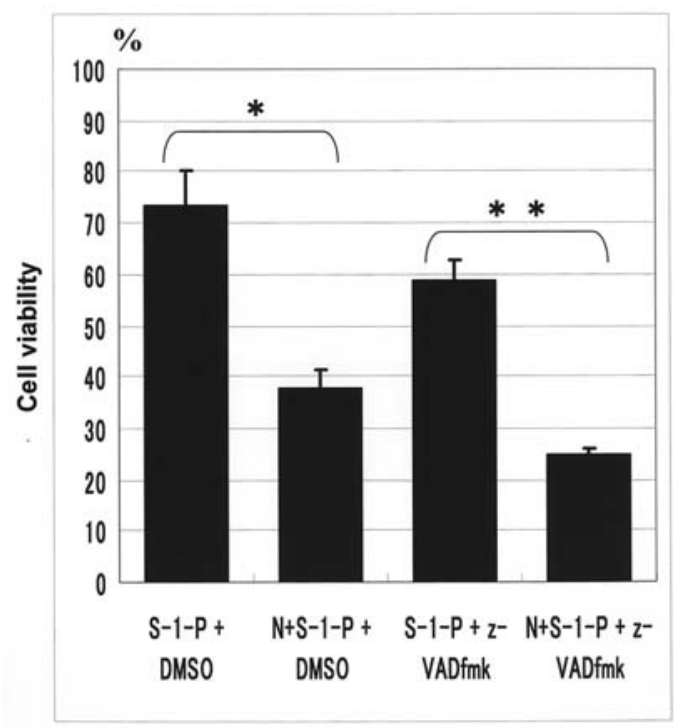

Figure 3. Effects of caspase inhibitors on S-1-P-induced cell death in HBL-2 cells. The effect of S-1-P on cell viability in the presence or absence of the pan-caspase inhibitor z-vad-FMK and with or without neuraminidase treatment was assessed using a WST-1 assay. The induction of cell death by S-1-P with or without neuraminidase treatment was not blocked by z-VAD-fmk. DMSO, dimethyl sulfoxide (control); $\mathrm{N}$, with neuraminidase treatment. ${ }^{*} \mathrm{P}=0.0014,{ }^{* *} \mathrm{P}=0.0001$ by Student's t-test. Values represent the mean cell viability $\pm \mathrm{SD}$. The experiment was performed in triplicate.

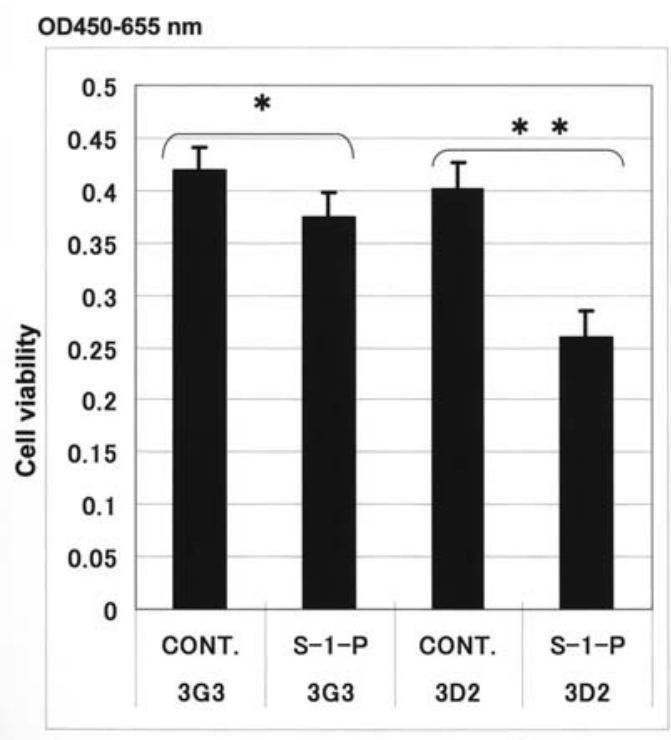

Figure 4. S-1-P-induced cell death in HBL-8 clones. Effect of S-1-P on the viability of HBL-8 clones was assessed by a WST-1 assay. S-1-P was less effective at inducing cell death in the $3 \mathrm{G} 3$ clone than the 3D2 clone. ${ }^{*} \mathrm{P}=0.0683,{ }^{* *} \mathrm{P}=0.0023$ as determined by Student's t-test. Values represent the mean cell viability $\pm \mathrm{SD}$. The experiment was performed in triplicate. CONT, control experiment (without S-1-P).

neuraminidase treatment (35\% and 25\%, respectively; Fig. 2b). Cell death induced by S-1-P with or without neuraminidase treatment was not blocked by z-VAD-fmk (Fig. 3). In contrast, cell death by S-1-P was slightly enhanced by z-VAD-fmk. Also, S-1-P significantly reduced the viability of both the 3D2 and $3 \mathrm{G} 3$ clones of HBL-8 cells, although the $3 \mathrm{G} 3$ cells were less sensitive than the 3D2 cells (Fig. 4). 
a

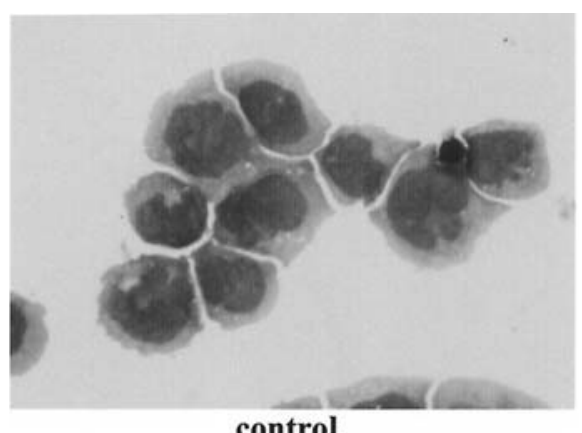

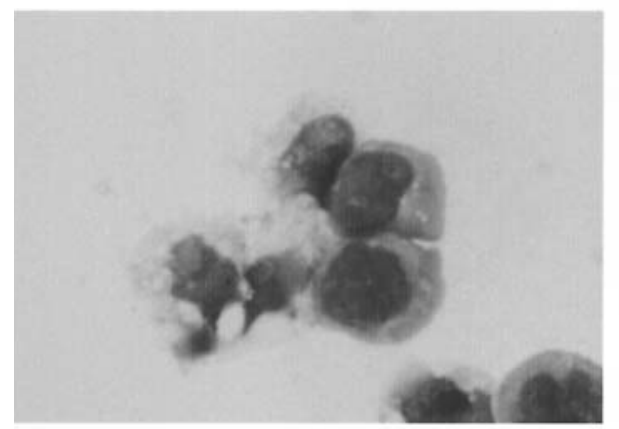

Neuraminidase(-) sphingosine-1-p

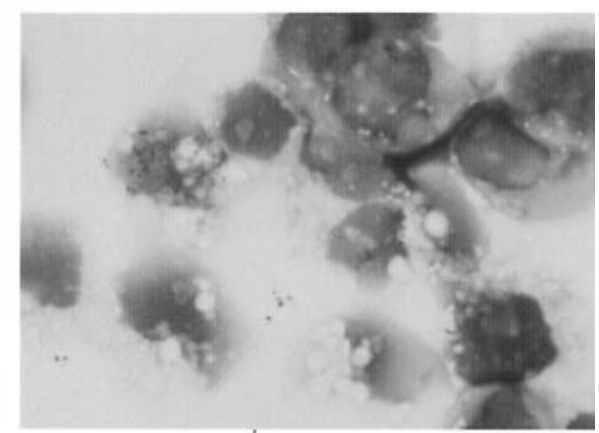

Neuraminidase(+) sphingosine-1-p

b

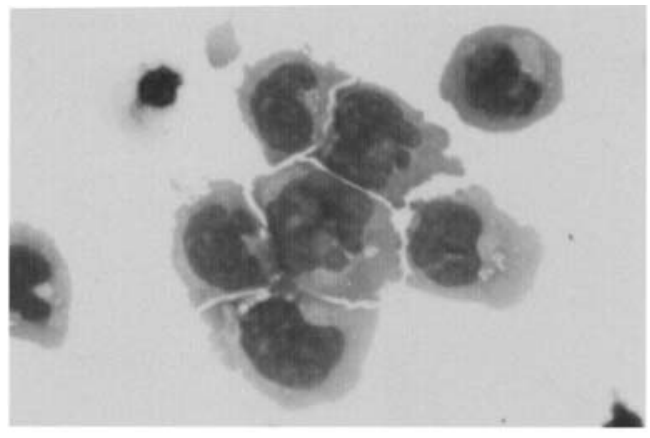

control

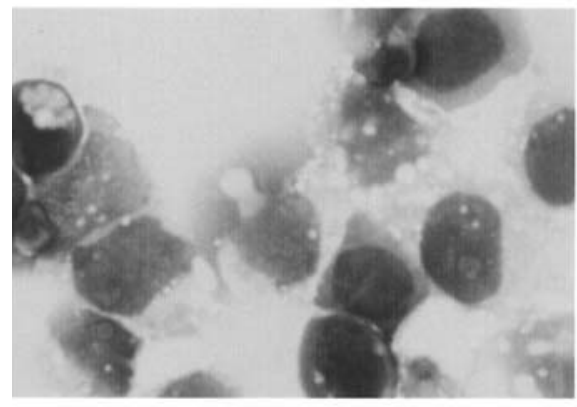

Neuraminidase(-) sphingosine

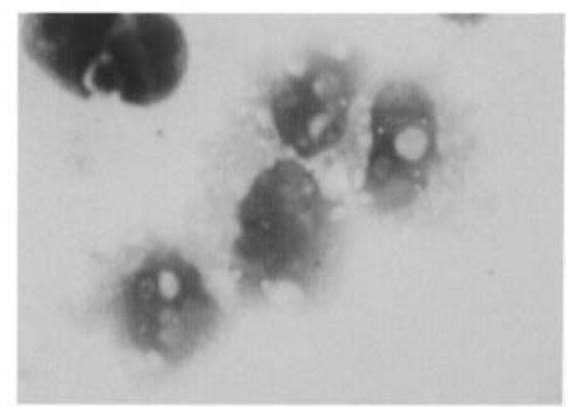

Neuraminidase(+) sphingosine

Figure 5. Morphology of sphingolipid-treated HBL-2 cells. HBL-2 cells were incubated with S-1-P (a) or sphingosine (b) for 60 min. The cells showed swelling and cytoplasmic vacuoles in both conditions with or without neuraminidase treatment.

Morphologic changes during sphingolipid-induced cell death. HBL-2 lymphoma cells incubated with S-1-P or sphingosine showed swelling and the appearance of cytoplasmic vacuoles (Fig. 5) both with or without neuraminidase treatment.

Annexin-V assay. Treatment of HBL-2 cells with S-1-P caused an increase in the number of PI-positive cells compared to controls. This increase was enhanced by neuraminidase pretreatment (Fig. 6).

\section{Discussion}

$\mathrm{S}-1-\mathrm{P}$ is a novel inhibitor of $\mathrm{T}$ cell proliferation and maintains the homeostatic immune systems (31). S-1-P also triggers 
(a)

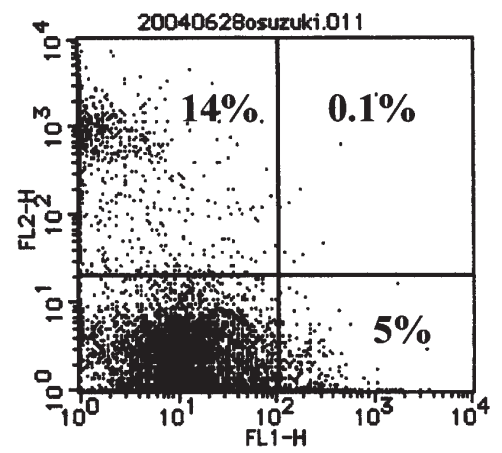

(c)

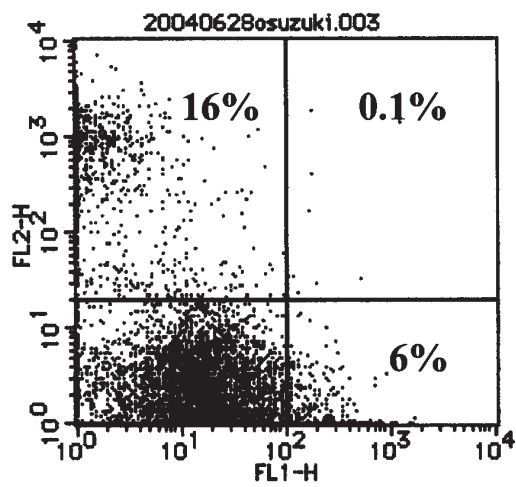

(b)

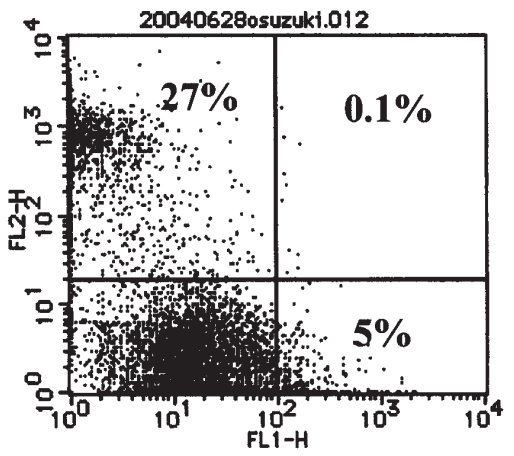

(d)

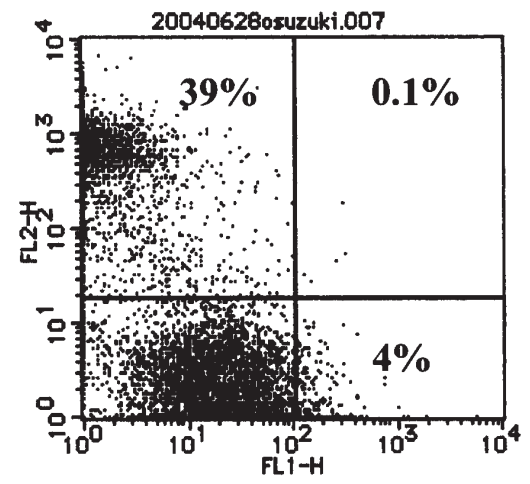

Figure 6. Annexin-V assay on the HBL-2 cell line. Annex-V-FITC binding was assessed following treatment with (a) control, (b) S-1-P alone, (c) neuraminidase alone or (d) S-1-P with neuraminidase pretreatment. The fluorescein fluorescence was plotted on the X-axis, and the PI fluorescence was plotted on the Yaxis. Neuraminidase enhanced the ability of S-1-P to increase the number of PI-positive cells.

Induction of cell death

by Sphingosine-1-phosphate, Sphingosine

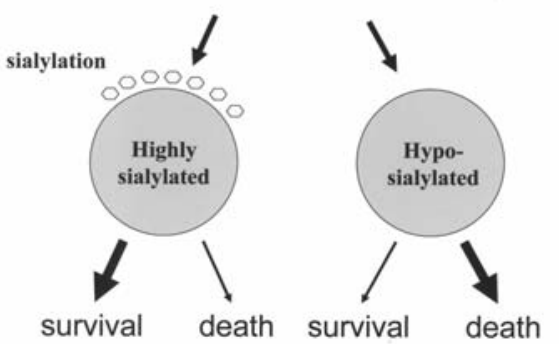

Figure 7. Schematic representation of the relationship between cell surface sialylation and sphingolipid-induced cell death. A highly sialylated cell surface protects lymphoma cells from sphingolipid-induced cell death, whereas hyposialylation enhances the sensitivity of cells to sphingolipidinduced cell death.

apoptotic signals in human hepatic myofibroblasts $(24,25)$ and induces the death of several types of cells, including hepatoma cells (26). In the present study, we showed that a highly sialylated cell surface can protect lymphoma cells from S-1-P- or sphingosine-induced cell death and that hypo- sialylation increases the sensitivity of the cells to these agents (summarized in Fig. 7). In addition, results from the Annexin-V assay and morphological evaluation indicate that S-1-Pinduced cell death is due to necrosis rather than apoptosis. These data suggest that cell surface sialylation plays an important role in S-1-P-induced necrotic cell death of human B cell lymphomas.

CDw76 is reported to be an $\alpha 2,6$-sialylated ganglioside (38). Cell surface desialylation with neuraminidase reduced the binding of an anti-CDw76 monoclonal antibody that recognizes $\alpha 2,6$-sialylated ganglioside. Therefore, alteration of gangliosides to asialo-gangliosides may be associated with a perturbation of the cell membrane leading to enhanced susceptibility of lymphoma cells to S-1-P and sphingosine.

There was a significant difference in the susceptibility of the HBL-8 clones to S-1-P. Our results suggest that this may be due to different extents of cell surface sialylation; specifically, increased cell surface sialylation (clone 3G3) corresponds to a reduced susceptibility of the cells to S-1-Pinduced cell death. When injected into SCID mice, the highly sialylated 3G3 clone is more metastatic than the hyposialylated 3D2 clone (10). Together with our findings, this suggests that the higher cell surface sialylation in the $3 \mathrm{G} 3$ clone protects 
them from S-1-P-induced cell death in the bloodstream or at distant target organs, leading to a higher metastatic rate.

The EDG family G-protein-coupled receptors have been shown to be receptors for S-1-P $(24,25,31)$. EDG receptor-1 was not expressed on the surface of HBL-2 or HBL-8 cells (data not shown). Therefore, the induction of cell death by $\mathrm{S}-1-\mathrm{P}$ is not mediated by an EDG receptor, and S-1-P acts directly on cell death of HBL-2 and HBL- 8 cells. Further study is needed to determine the signaling mechanisms mediating $\mathrm{S}-1-\mathrm{P}$-induced cell death.

In conclusion, cell death induced in human B cell lymphoma by S-1-P or sphingosine appeared to be influenced by cell surface sialylation. Investigation of the relationship between cell surface sialylation and sphingolipid-induced cell signaling may provide new insight into the treatment of hematological malignancies.

\section{Acknowledgements}

We would like to thank Mrs. M. Satoh for her technical assistance and advice.

\section{References}

1. Varki A: Sialic acids as ligands in recognition phenomena. FASEB J 11: 248-255, 1997.

2. Schirrmacher V, Altefogt P, Fogel M, Dennis JW, Waller CA, Barz D, Schwartz V, Cheingsong-Popov R, Springer G, Robinson PJ, Nebe T, Brossmer W, Vlodavsky I, Paweletz N, Zimmermann H-P and Uhlenbruck G: Importance of cell surface carbohydrates in cancer cell adhesion, invasion and metastasis. Invasion Metastasis 2: 313-360, 1982.

3. Takano R, Muchmore E and Dennis JW: Sialylation and malignant potential in tumor cell glycosylation mutants. Glycobiology 4: 665-674, 1994.

4. Altevogt P, Fogel M, Cheingsong-Popov R, Dennis J, Robinson P and Schirrmacher V: Different patterns of lectin binding and cell surface sialylation detected on related high- and low-metastatic tumor lines. Cancer Res 43: 5138-5144, 1983.

5. Kijima-Suda I, Miyamoto Y, Toyoshima S, Itho M and Osawa T: Inhibition of experimental pulmonary metastasis of mouse colon adenocarcinoma 26 sublines by a sialic acid: nucleoside conjugate having sialyltransferase inhibiting activity. Cancer Res 46: 858-862, 1986.

6. Yogeeswaran G and Salk PL: Metastatic potential is positively correlated with cell surface sialylation of cultured murine tumor cell lines. Science 212: 1514-1516, 1981.

7. Moergenthaler J, Kemmner W and Brossmer R: Sialic acid dependent adhesion to collagen IV correlates with in vivo tumorigenicity of the human colon carcinoma sublines HCT116, HCT116a and HCT 116b. Biochem Biophys Res Commun 171: 860-866, 1990.

8. Dennis JW, Waller C, Timpl R and Schirrmacher V: Surface sialic acid reduces attachment of metastatic tumor cells to collagen type IV and fibronectin. Nature 300: 274-276, 1982.

9. Fogel M, Altefogt $\mathrm{P}$ and Schirrmacher V: Metastatic potential severely altered by changes in tumor cell adhesiveness and cellsurface sialylation. J Exp Med 157: 371-376, 1983.

10. Abe M, Suzuki O, Tasaki K, Tominaga K and Wakasa H: Analysis of lectin binding properties on human Burkitt's lymphoma cell lines that show high spontaneous metastasis to distant organs in SCID mice: the binding sites for soybean agglutinin lectin masked by sialylation are closely associated with metastatic lymphoma cells. Pathol Int 46: 977-983, 1996.

11. Irimura T, Tressler RJ and Nicolson GL: Sialoglycoproteins of murine RAW117 large cell lymphoma/lymphosarcoma sublines of various metastatic colonization properties. Exp Cell Res 165: 403-416, 1986.

12. Suzuki O, Nozawa Y, Kawaguchi T and Abe M: Phaseolus vulgaris leukoagglutinating lectin-binding reactivity in human diffuse large B cell lymphoma and its relevance to the patient's clinical outcome: lectin histochemistry and lectin blot analysis. Pathol Int 49: 874-880, 1999.
13. Suzuki O, Nozawa Y, Kawaguchi T and Abe M: Alpha-2,6sialylation of L-PHA reactive oligosaccharides and expression of N-acetyl glucosaminyltransferase $\mathrm{V}$ in human diffuse large $\mathrm{B}$ cell lymphoma. Oncol Rep 10: 1759-1764, 2003.

14. Klem S and Schauer R: Sialic acids in molecular and cellular interactions. Int Rev Cytol 175: 137-240, 1997.

15. Baum LG, Derbin K, Perillo NL, Wu T, Pang M and Uittenboggart C: Characterization of terminal sialic acid linkages on human thymocytes. J Biol Chem 271: 10793-10799, 1996.

16. Marer NL and Skacel PO: Up-regulation of $\alpha 2,6$ sialylation during myeloid maturation: a potential role in myeloid cell release from the bone marrow. J Cell Physiol 179: 315-324, 1999.

17. Keppler OT, Peter ME, Hinderlich S, Moldenhauer G, Stehling P, Schmitz I, Schwartz-Albiez R, Reutter W and Pawlita M: Differential sialylation of cell surface glycoconjugates in a human B lymphoma cell line regulates susceptibility for CD95(APO-1/ Fas)-mediated apoptosis and for infection by a lymphotropic virus. Glycobiology 9: 557-569, 1999.

18. Peter ME, Hellbardt S, Schwartz-Albiez R, Westendorp MO, Walczak H, Moldenhauer G, Grell M and Krammer PH: Cell surface sialylation plays a role in modulating sensitivity towards APO-1-mediated apoptotic cell death. Death Differ 2: 163-171, 1995 .

19. Suzuki O, Nozawa Y and Abe M: Sialic acids linked to glycoconjugates of Fas regulate the caspase-9-dependent and mitochondria-mediated pathway of Fas-induced apoptosis in Jurkat T cell lymphoma. Int J Oncol 23: 769-774, 2003.

20. Keppler OT, Hinderlich S, Langner J, Schwartz-Albiez R, Reutter W and Pawlita M: UDP-GlcNAc2-epimerase: a regulator of cell surface sialylation. Science 284: 1372-1376, 1999.

21. Suzuki O, Nozawa Y, Kawaguchi T and Abe M: UDP-GlcNAc2epimerase regulates cell surface sialylation and cell adhesion to extracellular matrix in Burkitt's lymphoma. Int J Oncol 20: 1005-1011, 2002.

22. Cuvillier O, Edsall L and Spiegel S: Involvement of sphingosine in mitochondria-dependent Fas-induced apoptosis of type II Jurkat T cells. J Biol Chem 275: 15691-15700, 2000.

23. Spiegel S and Milstien S: Sphingosine 1-phosphate, a key cell signaling molecule. J Biol Chem 277: 25851-25854, 2002.

24. Davaille J, Gallois C, Habib A, Li L, Mallat A, Tao J, Levade T and Lotersztajn S: Antiproliferative properties of sphingosine 1-phosphate in human hepatic myofibroblasts. J Biol Chem 275: 34628-34633, 2000.

25. Davaille J, Li L, Mallat A and Lotersztajn S: Sphingosine-1phosphate triggers both apoptotic and survival signals for human hepatic myofibroblasts. J Biol Chem 277: 37323-37330, 2000.

26. Hung $\mathrm{W}$ and Chuang L: Induction of apoptosis by sphingosine1-phosphate in human hepatoma cells is associated with enhanced expression of bax gene product. Biochem Biophys Res Commun 229: 11-15, 1996.

27. Smith WL and Merrillx AH Jr: Sphingolipid metabolism and signaling minireview series. J Biol Chem 277: 25841-25842, 2002.

28. Prieschl EE, Csonga R, Novotny V, Kikuchi GE and Baumruker T: The balance sphingosine and sphingosine-1phospate decisive for mast cell activation after Fc epsilon receptor I triggering. J Exp Med 190: 1-8, 1999.

29. Yatomi Y, Ruan F, Hakomori S and Igarashi Y: Sphingosine-1phosphate: a platelet-activating sphingolipid released from agoniststimulated human platelets. Blood 86: 193-202, 1995.

30. Yang L, Yatomi Y, Miura Y, Satoh K and Ozaki Y: Metabolism and functional effects of sphingolipids in blood cells. Br J Haematol 107: 282-293, 1999.

31. Jin Y, Knudsen E, Wang L, Bryceson Y, Damaj B, Gessani S and Maghazachi AA: Sphingosine-1-phosphate is a novel inhibitor of T-cell proliferation. Blood 101: 4909-4915, 2003.

32. Dorsam G, Graeler MH, Seroogy C, Kong Y, Voice JK and Goetz EJ: Transduction of multiple effects of sphingosine 1phosphate (S-1-P) on T cell functions by the S-1-P1 G proteincoupled receptor. J Immunol 171: 3500-3507, 2003.

33. Hannunn YA, Loomis CR, Merrill AH and Bell RM: Sphingosine inhibition of protein kinase $\mathrm{C}$ activity and of phorbol dibutyrate binding in vitro and in human platelets. J Biol Chem 261: 12604-12609, 1986.

34. Ohta H, Sweeney A, Masamune A, Yatomi Y, Hakomori S and Igarashi Y: Induction of apoptosis by sphingosine in human leukemic HL-60 cells: a possible endogenous modulator of apoptosis DNA fragmentation occurring during phorbol esterinduced differentiation. Cancer Res 55: 691-697, 1995. 
35. Iwata M, Herrington J and Zager RA: Sphingosine: a mediator of acute renal tubular injury and subsequent cytoresistance. Proc Natl Acad Sci USA 92: 8970-8974, 1995.

36. Ohta H, Yatomi Y, Sweeney A, Hakomori S and Igarashi Y: A possible role of sphingosine in induction of apoptosis by tumor necrosis factor- $\alpha$ in human neutrophils. FEBS Lett 355: 267-270, 1994.
37. Abe M, Nozawa Y, Wakasa H, Ohno H and Fukuhara S: Characterization and comparison of two newly established Epstein-Barr virus-negative lymphoma B-cell lines. Cancer 61: 483-490, 1988.

38. Kniep B, Schakel K, Nimtz M, Schwartz-Albiez R, Schmitz M, Northoff H, Vilella R, Gramatzki M and Rieber EP: Differential expression of alpha2-6 sialylated polylactosamine structures by human B and T cells. Glycobiology 9: 399-406, 1999. 